\title{
Investigation of physical and mechanical properties of polyaniline/MMT nanocomposites
}

\author{
Hamid Gholami, Alireza Shakeri* and Vahid Saadattalab
}

School of Chemistry, College of Science, University of Tehran,3174878564, Tehran, Tehran, Iran

\begin{tabular}{l} 
C H R O N I C L E \\
\hline Article history: \\
Received March 2, 2017 \\
Received in revised form \\
June 20, 2017 \\
Accepted June 26, 2017 \\
Available online \\
June 26, 2017 \\
\hline Keywords: \\
Polyaniline \\
Montmorillonite \\
Nanocomposites \\
Physical and mechanical \\
properties
\end{tabular}

\section{Introduction}

Polymer nano-composites are a new class of advanced materials and commonly defined as consisting of two (or more) phases, a polymer matrix, and additives that have at least one dimension in the nanometre range commonly $1-100 \mathrm{~nm}^{1}$ Nano-composites show a noticeable increase in thermal, mechanical and optical properties compared to their pure or conventional composites. ${ }^{2}$ In the past two decades, polymer Nano composites have attracted considerable interests in both academia and industry, due to their good mechanical properties like elastic stiffness and strength with only a small amount of Nano additives (commonly 2-5\%). ${ }^{3}$ This is due to the large surface area to volume ratio of nanomaterials when compared to the micro and macro materials. Conducting polymers are polymer materials with metallic and semiconductor characteristics, a combination of properties not exhibited by any other known material ${ }^{4}$. Discovery of polysulphur nitride (SN) which becomes superconducting at low temperatures was the first revolution about conducting polymers ${ }^{5}$. Another great revolution came

\begin{abstract}
ABS T R A C T
Polyaniline (PANI) was synthesized chemically in an acidic medium in the presence of were prepared in the presence of various amounts of modified clay (from 1 to 5 wt.\%) by solution casting method. The free standing film of polyaniline and PANI/clay nano-composites SEM image, and XRD pattern. Thermal stability was also studied by TGA analysis, electrical conductivity was measured by four point probe technique and mechanical properties were studied by tensile strength. The PANI/clay nano-composites thermal and mechanical properties were observed to be remarkably improved. For example, polyaniline containing nano-clay has less weight loss compared to pure polyaniline. In addition Young's modulus and strength at
break point was increased in the case of polyaniline containing nano-clay The importance of our work is to provide a narrow look on the thermal and physical properties of polyaniline by the incorporation of montmorillonite into its structure as well as investigation of the conductivity of PANI/MMT nanocomposites as a potential conductive polymer to be used in solar cells or have corrosion protection applications.
\end{abstract}

(C) 2017 Growing Science Ltd. All rights reserved. 
in 1977 with the discovery of electrical conduction in doped polyacetylene by Shirakawa and et al. ${ }^{6}$ Intrinsically conducting polymers (ICPs) are inherent conductivities and have a low energy transition, low ionization potential and high electron affinity ${ }^{7}$. Some other ICPs include conjugated organic polymers such as polypyrrole, polythiophene, polyaniline etc. These polymers consist of alternating single and double bonds where creating an extended $\pi$ network by these bounds results in the conduction as a consequence of electron movement in the $\pi$ framework. Among the ICPs, Polyaniline(PANI) has attracted great attention due to its easy synthesis process, relative environmental and thermal stability, ${ }^{8}$ high electrical conductivity, ${ }^{9,10}$ relatively low cost ${ }^{11}$ and wide range of applications such as secondary batteries,${ }^{12,13}$ solar cell, ${ }^{14,}{ }^{15}$ corrosion devices, ${ }^{16}$ organic light emitting diodes, ${ }^{17}$ and bio/chemical sensors. ${ }^{18}$ ICPs exhibit poor mechanical properties and are also thermally unstable. ${ }^{19}$ Another drawback of ICPs is their lack of solubility in common solvent due to their rigid backbone which results in their limited processability. ${ }^{20}$ Various procedures have been applied to improve their processability. Some of these procedures in the case of polyaniline include copolymerization of aniline with other monomers, ${ }^{21}$ incorporation of a polymeric chain or flexible alkyl chain into the PANI backbone ${ }^{22}$ composite preparation of polyaniline and other conventional polymers $^{23}$ and dispersion of nano-materials into the polyaniline matrix ${ }^{24}$. Creating polyaniline nanocomposites by adding nano particles is a promising way to overcome its poor mechanical properties. In recent years, polymer-clay nanocomposites have received considerable research attention because of the remarkable improvement in physical, ${ }^{25}$ and mechanical properties, ${ }^{26,27}$ such as high modulus ${ }^{28}$ increased strength and heat resistance. ${ }^{29}$ Montmorillonite (MMT) is a clay mineral that consists of two fused silicate tetrahedral sheets sandwiching an edge shared octahedral sheet of either magnesium or aluminum hydroxide. ${ }^{30}$ Clay is usually modified to make it compatible with the organic system including organic polymers. Modification of clay can be done by substitution of the exchangeable cations $\left(\mathrm{Na}^{+}, \mathrm{Ca}^{2+}\right)$ with some organic molecules (usually organic cations such as alkyl ammonium or phosphonium). ${ }^{31}$

In this work, which is the first step of future works, we report the PANI/ MMT nano-composite preparation by solution casting method and investigate the effect of nano clay amount on the mechanical, thermal and electrical properties of polyaniline. Researches on mechanical properties of polyaniline nano-composites were only a few cases reported in the literature. ${ }^{1,26}$ Solar cells are highly dependent to a high conductive material to collect the electrons generated in the p-n junction system. Other than a high conductive material, it is desirable to find an electrode compatible with the absorber layer material especially those with inorganic absorbers such as CZTS and CIGS. ${ }^{32}$

\section{Results and Discussion}

\subsection{FT-IR spectra}

PANI/MMT nano-composites (Cloisite 15A) were characterized using FT-IR technique. Fig.1 shows that the characteristic peaks of pure polyaniline appear at $1586,1491,1288,1161 \mathrm{~cm}^{-1}$. In these spectra absorption, peaks at $1491 \mathrm{~cm}^{-1}$ are attributed to the stretching mode of $\mathrm{C}=\mathrm{C}$ in the benzoid rings and absorption peaks at $1586 \mathrm{~cm}^{-1}$ are attributed to the stretching vibration of $\mathrm{C}=\mathrm{C}$ in the quinoid rings. Peaks at $1288 \mathrm{~cm}^{-1}$ are attributed to the stretching mode of $\mathrm{C}-\mathrm{N}$ in secondary amine groups and the peaks appeared at $1161 \mathrm{~cm}^{-1}$ are assigned to the stretching mode of the $\mathrm{C}=\mathrm{N}$ for quinoid rings and Fig. 2 shows that the characteristic peaks of Cloisite 15A appear at $1045 \mathrm{~cm}^{-1}$ (Si-O), $917 \mathrm{~cm}^{-1}$ (Al-O), 523 $\mathrm{cm}^{-1}$ (Si-O-Al) and peaks appeared at $3620,2928,2851 \mathrm{~cm}^{-1}$ are attributed to the organic modifier of nano-clay. According to Fig. 3 it's determined that the characteristic peaks of polyaniline in a nanocomposite shift in lower wavenumbers $\left(, 1585,1288,1154 \mathrm{~cm}^{-1}\right)$ in addition peaks appear at 2921, $2851 \mathrm{~cm}^{-1}$ (attributed to nano clay). Therefore FT-IR spectra confirm the incorporation of nano-clay particles into polyaniline matrix using solution mixing method. 


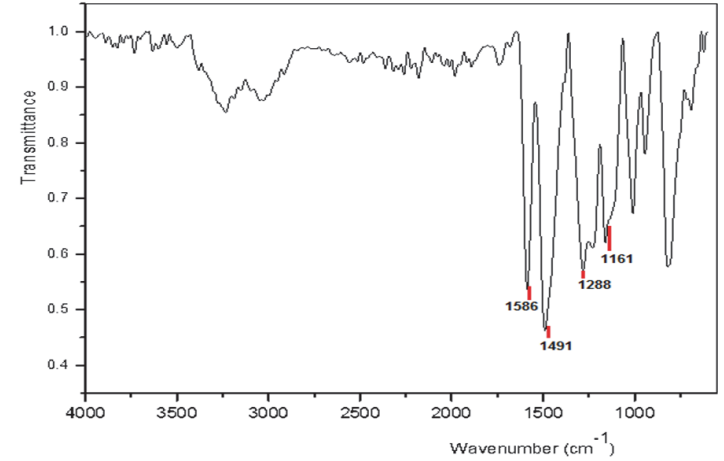

Fig. 1. FT-IR spectra of pure polyaniline

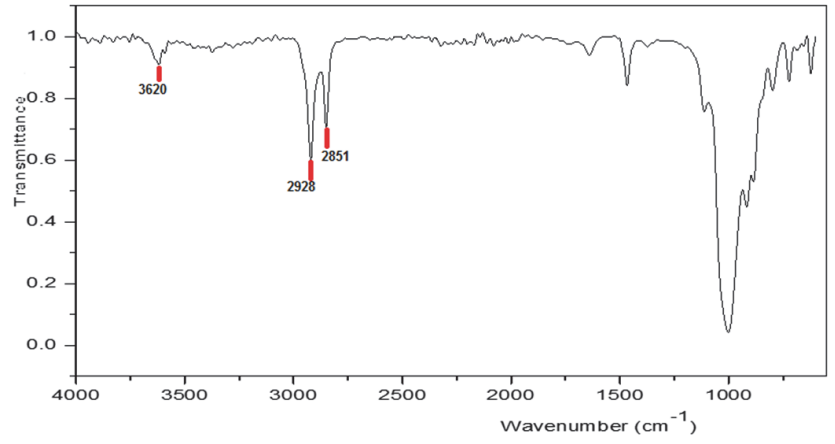

Fig. 1. FT-IR spectra of modified Clay nanoparticle (MMT)

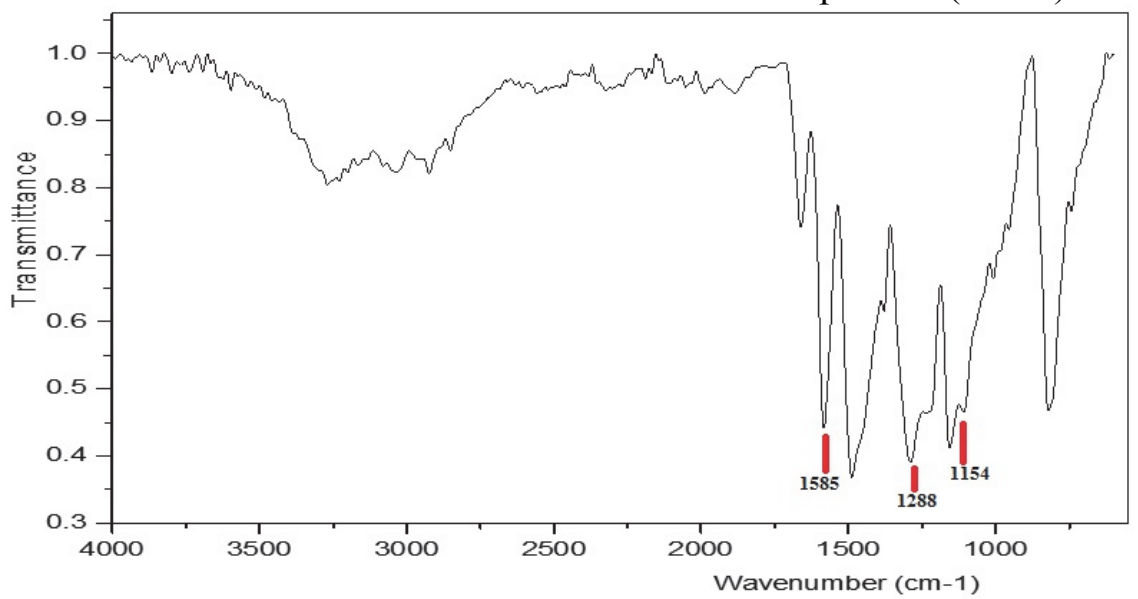

Fig. 2. FT-IR spectra of polyaniline/MMT nano-composite

\subsection{XRD patterns}

Nano composite of polyaniline/MMT were characterized using X-ray diffraction pattern analysis. Xray diffractometer (Philips PW-1840) with $\mathrm{Cu}-\mathrm{k} \alpha$ radiation $(\lambda=1.5418 \AA$ ) source in $2 \theta$ scan mode was used to record the XRD pattern. Cloisite $15 \mathrm{~A}$ has three peaks in $2 \theta=2.12,2 \theta=2.81,2 \theta=7.29$. Fig. 4 shows the XRD pattern of polyaniline/MMT nano-composite. This pattern shows a broad peak approximately in 2 $2=15-35$ for amorphous polyaniline and also no peaks appears for MMT ( $2 \theta \leq 7.29)$ and this illustrates the formation of exfoliated state of PANI/MMT nano-composite. In this state, polyaniline chains increase d-spacing of nano-MMT so that there is not a considerable interaction between silicate layers. In order to realize the maximum benefit of a nano-composite, the exfoliated state is the ultimate goal, because this will present the maximum interfacial interaction between the polymer and nano-particle.

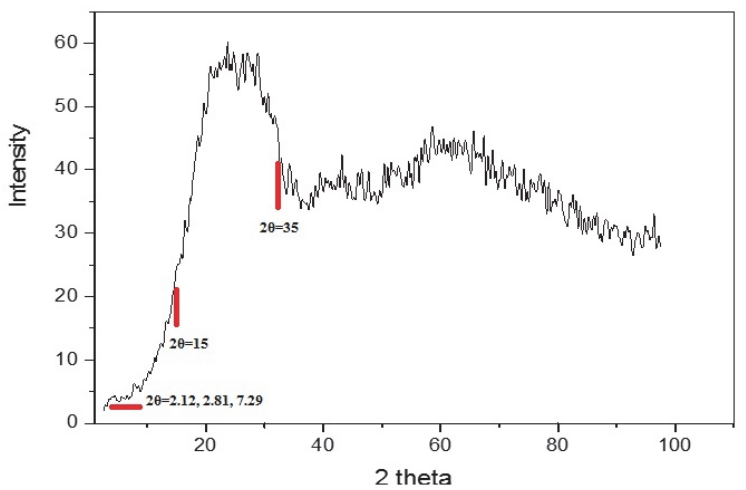

Fig. 4. XRD pattern of PANI/MMT 


\subsection{Scanning electron microscopy (SEM) study}

The surface morphology of PANI/MMT was studied by SEM as shown in Fig. 5. According to micrograph of PANI/MMT nano-composite, nano-MMT was incorporated into polyaniline matrix with a diameter size of less than $50 \mathrm{~nm}$.

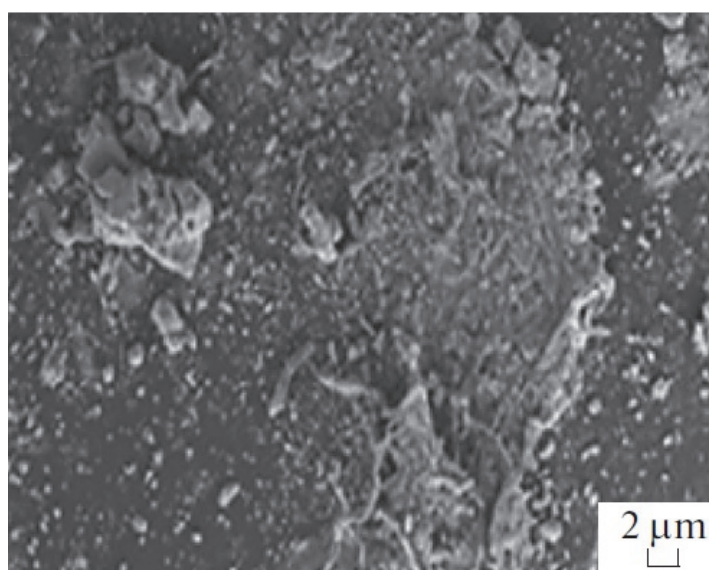

Fig. 5. SEM image of PANI/MMT

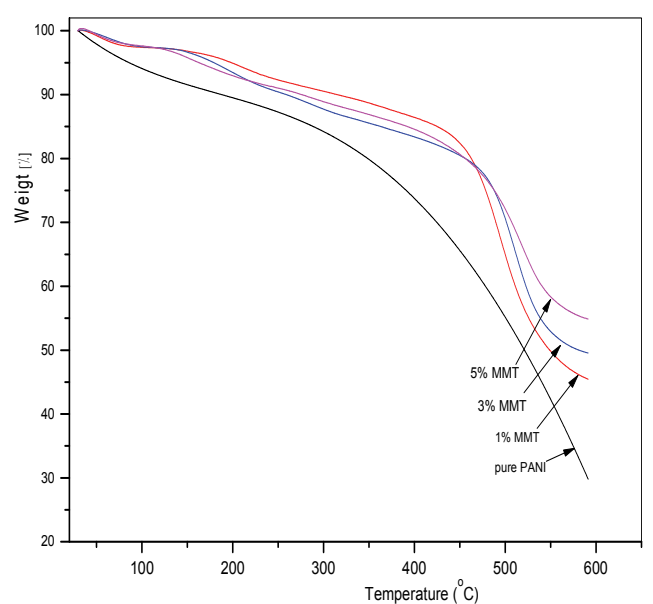

Fig. 6. TGA of polyaniline and PANI/MMT nanocomposite

\subsection{Thermo gravimetric analysis (TGA)}

TGA instrument (Q50 V6.3 Build 189) was used to study the thermal stability of polyaniline and its nano-composites. In this analysis, the weight loss was measured within the range of ambient temperature to $600{ }^{\circ} \mathrm{C}$. According to TGA curve of polyaniline and its composites (Fig. 6) pure polyaniline has three major stages of weight loss, the first weight loss is due to loss of water and volatile solvent up to around $120^{\circ} \mathrm{C}$ and the second weight loss is attributed to the loss of solvent (NMP) that was used for film preparation, massive weight loss starts from $380{ }^{\circ} \mathrm{C}$ due to the thermo-oxidative decomposition of polyaniline and may involve the degradation products such as N-phenylaniline, methane, acetylene, carbazole, etc. The highest rate of weight loss occurs at $518{ }^{\circ} \mathrm{C}$, in addition, the residual at $600{ }^{\circ} \mathrm{C}$ is 29.31 percent for pure polyaniline. TGA curve of PANI/MMT nano-composites shows the significant improve in thermal stability compared to pure polyaniline so that the weight loss for polyaniline containing $1 \%$ nano-clay reaches $45.46 \%$ and the thermo-oxidative degradation of nano-composite starts at $440{ }^{\circ} \mathrm{C}$ and its highest rate is at $492{ }^{\circ} \mathrm{C}$, in case of nano-composites containing 3 and 5 of percent nano-clay, residual was reduced to $49.46 \%$ and $54.78 \%$ respectively and the highest rate of thermo-oxidative decomposition of nano-composites reached $507{ }^{\circ} \mathrm{C}$ and $515{ }^{\circ} \mathrm{C}$ respectively. These results confirm the positive effect of MMT for improvement of polyaniline thermal stability.

\subsection{Mechanical properties}

In order to study mechanical properties, polyaniline, and its nano-composites were prepared as free standing film using solution casting method, and the tensile strength was measured using a universal testing machine (Instron, 5566 USA) at room temperature. The test was carried out at a strain rate of $5 \mathrm{~mm} . \mathrm{min}^{-1}$ until the sample broke. Stress- strain curve is shown in Fig 7. It's clear from the stress- strain curve that incorporation of nano-clay into polyaniline matrix improved the mechanical properties so that Young's modulus from 1.91Gpa for pure polyaniline reached 3.12Gpa for PANI/MMT 5\%. In addition strength at break point increased but elongation decreased compared to pure polyaniline. This results due to the limitation of polyaniline chain movement. Results of mechanical properties are summarized in Table 1. 


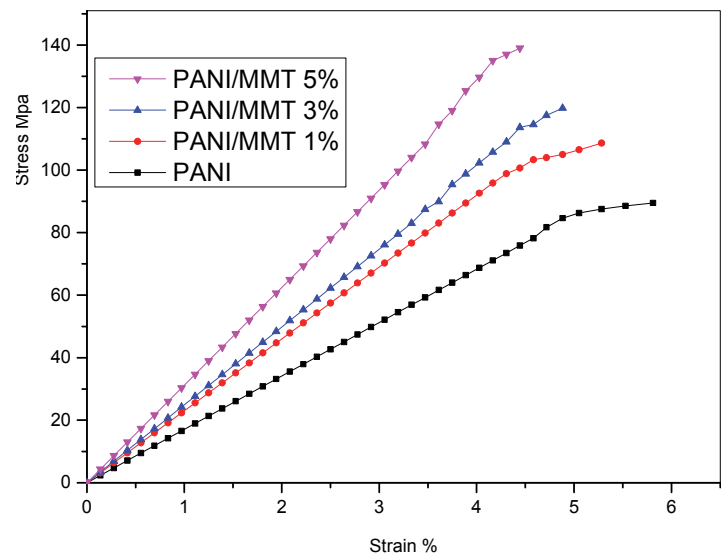

Fig. 7. Stress-strain curve of pure polyaniline a PANI/MMT nano-composites

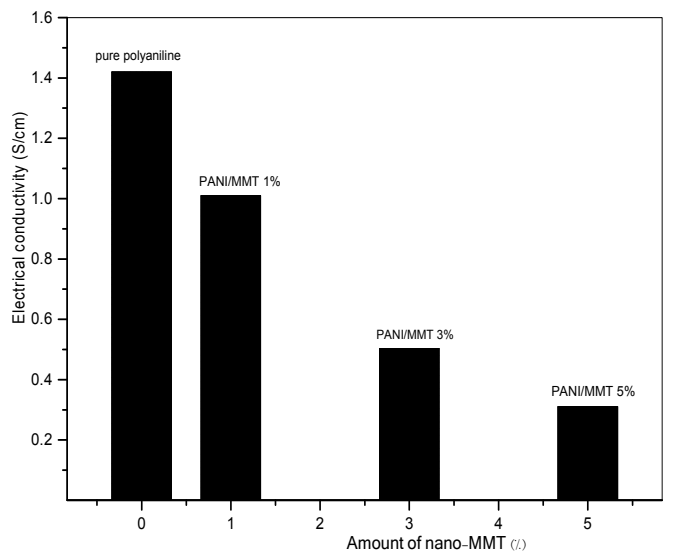

Fig. 8. Electrical conductivity of polyaniline and PANI/MMT nano-composites

Table 1. Mechanical properties of pure polyaniline and PANI/MMT nano-composites

\begin{tabular}{cccc}
\hline & $\begin{array}{c}\text { Young's modulus } \\
\text { (Gpa) }\end{array}$ & $\begin{array}{c}\text { Strength at break } \\
\text { point (Mpa) }\end{array}$ & Elongation (\%) \\
\hline Pure Polyaniline & 1.91 & 89.5 & 5.88 \\
PANI/MMT 1\% & 2.3 & 108 & 5.27 \\
PANI/MMT 3\% & 2.42 & 119.7 & 4.89 \\
PANI/MMT 5\% & 3.12 & 138.8 & 4.43 \\
\hline
\end{tabular}

\subsection{Electrical conductivity}

The electrical conductivity of polyaniline and its nano-composites were measured according to ASTM.D 4496-84 by a homemade four point probe. In this system, four electrodes were placed on PVC layer. The free standing film of polyaniline and its nano-composites were prepared in size of 7 $\mathrm{cm}^{*} 1 \mathrm{~cm}$ and an average diameter of $25 \mu \mathrm{m}$. The constant electrical current was applied between outer electrodes and the voltage was measured between inner electrodes. The electrical conductivity was calculated from Eq. (1)

$$
\text { o }=\frac{1}{R}=\frac{Z . I}{X . Y . \Delta E}
$$

In Eq. (1) $Z$ is the distance between inner electrodes (cm), $X$ and $Y$ are polymer film thickness $(\mathrm{cm})$ and width $(\mathrm{cm}), \mathrm{I}$ is applied current $(\mathrm{mA}), \Delta E$ is the value of voltage $(\mathrm{mV})$ that is measured between inner electrodes and 0 is electrical conductivity $(\mathrm{S} / \mathrm{cm})$. Fig. 8 shows the electrical conductivity of pure polyaniline and its nano-composites. It's clear from Fig. 8 that the conductivity of PANI/MMT was decreased compared to pure polyaniline because nano-MMT is an insulator, which blocks the interchain interactions between individual PANI chains. Initial weight loss $\left(\mathrm{T}_{0}\right)$ from the model dramatically increases at around $12.3 \mathrm{wt} \%$ PANI content.

\section{Conclusions}

Polyaniline was synthesized by chemical oxidation. Preparation of nano-composites was carried out by solution casting method using the solution of polyaniline in NMP solvent. Synthesis of polyaniline and preparation of its nano-composites was confirmed by FT-IR spectra, XRD pattern and SEM image. The shift in FT-IR peaks of the polyaniline-MMT samples suggests an interaction between the polyaniline-MMT nanocomposites. The morphological study from the SEM analysis shows the compact morphology with an increase in MMT. TGA analysis showed the increase in thermal stability of polyaniline by incorporation of nano-MMT into its matrix and the thermal stability of the system 
was increased with the increase of nano-MMT content in polyaniline matrix. With increasing MMT content in polyaniline matrix, the electrical conductivity of nano-composites was decreased compared to pure polyaniline Due to MMT which is an insulator. The tensile test showed the remarkable improvement in mechanical properties when polyaniline nano-composites were formed so that Young's modulus from $1.91 \mathrm{Gpa}$ for pure polyaniline reaches $3.12 \mathrm{Gpa}$ and tensile strength in break increased up to $55 \%$ in case of polyaniline containing five present of nano-MMT. As our next step we hope to find polyaniline/MMT nanocomposites as conductive and compatible counter electrode for CZTS and CIGS solar cells which are promising alternatives to fossil fuels.

\section{Acknowledgements}

We are glad to thank Department of Chemistry, University of Tehran for their financial support of our work.

\section{Experimental}

\subsection{Materials and Methods}

Aniline, hydrochloric acid, ammonia, acetone, Ammonium persulfate and 1-methyl 2-pyrrolidone (NMP) were all purchased from Merch Company (Germany). Aniline monomer was double distilled before use. Modified clay (Cloisite $(15 \mathrm{~A})$ nano particles were purchased from Southern Clay Company (US).

\subsection{Synthesis of Polyaniline}

Aniline $(15 \mathrm{ml}-0.164 \mathrm{~mol})$ was added into an aqueous solution of $1 \mathrm{M} \mathrm{HCl}$, Ammonium persulfate $(0.164 \mathrm{~mol})$ was dissolved in an aqueous solution of $1 \mathrm{M} \mathrm{HCl}$, then solution of APS was added drop wise into the aniline mixture and reaction was carried out at $0^{\circ} \mathrm{C}$, at time periods of 8 hours and during the reaction the mixture was stirred at a speed of $600 \mathrm{rpm}$. After adding all APS solution to complete the reaction, the mixture was continued to stir for 2 hours. Polyaniline as a black precipitate was recovered by vacuum filtration followed by washing with acetone, ethanol and distilled water to remove oligomers, hydrochloric acid, and any unreacted compound. Finally, polymer powder was dried in an oven for 24 hours at $60^{\circ} \mathrm{C}$.

\subsection{Preparation of PANI/MMT nano-composites}

PANI/ MMT nano-composites were prepared by solution casting method. In this method due to low solubility of Emeraldine salt polyaniline (ES-PANI) in NMP solvent, it was converted to Emeraldine base form (PANI-EB) by treating in ammonia solution (1.5M) for 8 hours. The polymer solution was obtained by slowly adding one gram of powdered polyaniline-EB into $60 \mathrm{ml}$ of NMP solvent for time periods of $10 \mathrm{~h}$. After adding all polyaniline, the mixture was stirred for 12 hours at $600 \mathrm{rpm}$. At the end of this time, mixture was filtered to separate the undissolved parts of polyaniline particles. The concentration of polyaniline in NMP was determined by the gravimetric method. $10 \mathrm{ml}$ of the solution was casted in a petri dish and after evaporation of the solvent at $60^{\circ} \mathrm{C}$ the values were determined to be $0.987 \mathrm{wt} . \%$.

\subsection{Preparation of PANI/MMT nano-composites film}

For the preparation of nano-composite films various amounts of nano-clay $(0-5 \%)$ was added into PANI/ NMP solution and stirred for 3 hours with a magnetic stirrer and then the PANI/Clay mixtures in NMP were exposed to the ultrasonic waves for 5 min to get better dispersions of nanoparticles. 
Finally, $45 \mathrm{ml}$ of the mixture was casted in the Petri dish for preparation PANI/ cay films. After evaporation of the solvent by dipping in distilled water, polymeric films were delaminated.

\section{References}

1. Soundararajah, Q. Y., Karunaratne, B. S. B., \& Rajapakse, R. M. G. (2009). Montmorillonite polyaniline nanocomposites: Preparation, characterization and investigation of mechanical properties. Mater. Chem. Phys., 113 (2) 850-855

2. Alexandre M., and Dubois P. (2000). Polymer layered silicate nanocomposites: preparation, properties and uses of a new class of materials, Mat. Sci. Eng., 28 (1-2) 1-63.

3. Eren B., Aydin R., and Eren E. (2014). Morphology and thermal characterization of montmorillonite/ polybenzimidazole nanocomposite. J. Therm. Anal. Calorim., 15 (2) 1525-1531.

4. Rangel V., Norma A, Sánchez L., Carlos R., and Felix, Francisco Rodríguez. (2014). Spectroscopy analyses of polyurethane/polyaniline IPN using computational simulation (Amber, MM+ and PM3 method). Polímeros, 24 (4) 453-463.

5. Ansari M. O., and Mohammad F. (2012). Thermal stability and electrical properties of dodecyl benzene sulfonic acid doped nanocomposites of polyaniline and multi-walled carbon nanotubes. Compos.: Part B, 43 (8) 3541-3548.

6. Shirakawa H., Louis E. J., MacDiarmid A. G., Chiang C. K., and Heeger, A. J. (1997). Synthesis of electrically conducting organic polymers: halogen derivatives of poly(acetylene) $(\mathrm{CH}) \mathrm{x}$. J. Chem. Soc., Chem. Commun., 16 (16) 578-579.

7. Unsworth J., Lunn B. A., Innis P.C., Jin Z., and et al. (1992). conducting polymer electronics. J. Intell. Mater. Syst. Struct. , 3 (3) 380-395.

8. Wang Y., Tran H. D., Liao L., Duan X., and Kaner R. B. (2010). Nanoscale morphology, dimensional control, and electrical properties of oligoanilines. J. Am. Chem. Soc., 132 (30) 1036510373.

9. Kim S., Ko J. M., and Chung I. J. (1996). Electrical conductivity change ofpolyaniline-dodecyl benzene sulfonic acid complex with temperature. Polym Adv Technol., 7 (7) 599-603.

10. Niziol J., Sniechowski M., Podraza A. J., and Pieli C. (2011). Alternative oxidizers in polyaniline synthesis. Polym. Bull., 66 (6) 761-770.

11. Olad A., and Rashidzadeh A. (2008). Preparation and anticorrosive properties of PANI/Na-MMT and PANI/O-MMT nanocomposites. Prog. Org. Coat., 62 (3) 293-298.

12. Ryu K., Kim K.M., Kang S. G., Lee G. L., Joo J., and Chang, SH.. (2010). Electrochemical and physical characterizationof lithium ionic salt doped polyaniline as a polymer electrode of lithium secondary battery. Synth Met. , 110 (3) 213-217.

13. Nakajima, T., \& Kawagoe, T. (1989). Polyaniline: Structural analysis and application for battery. Synth Met., 28 (1-2) 629-638.

14. Qiao Y., Li C., Bao S. J., and Bao Q.L. (2007). Carbon nanotube/polyaniline composite as anode material for microbial fuel cells. J. Power Sources, 170 (1) 79-84.

15. Chen J., Li B., Zheng J., Zhao J., Jing H., and Zhu Z. (2011). Polyaniline nanofiber/carbon film as flexible counter electrodes in platinum-free dye-sensitized solar cells. Electrochim Acta, 56 (12) 4624-4630.

16. Olad A., Barati M., and Shirmohammadi H. (2011). Conductivity and anticorrosion performance of polyaniline/zinc composites: Investigation of zinc particle size and distribution effect. Prog. Org. Coat., 72 (4) 599- 604.

17. Choi, M. R., Han, T. H., Lim, K. G., Woo, S. H., Huh, D. H., \& Lee, T. W. (2011). Soluble selfdoped conducting polymer compositions with tunable work function as hole injection/extraction layers in organic optoelectronics. Angew. Chem., 123 (28) 6398-6401.

18. Lin P., and Yan F. (2012). Organic thin film transistors for chemical and biological sensing. Adv. Mater., 24 (1) 34-51. 
19. Simões Fabio R., Bulhões Luís O. S., and Pereira, Ernesto C. (2009). Synthesis and characterization of conducting composites of polyaniline and carbon black with high thermal stability. Polímeros, 19 (1) 54-57.

20. Jaymand M. Recent progress in chemical modification of polyaniline. (2013). Prog. Polym. Sci., 38 (9) $1287-1306$.

21. Wang HL., Romero R J., Mates BR., Zhu Y., and Winokur, MJ. (2000). Effect of processing conditions on the properties of high molecular weight conductive polyaniline fiber. J. Polym. Sci. Part B Polym. Phys., 38 (1) 194-204.

22. Sakharov IY., Vorobiev A.,\& Castillo-Leon J.J. (2003). Synthesis of polyelectrolyte complexes of polyaniline and sulfonated polystyrene by palm tree peroxidase. Enzyme Microb. Technol., 33 (5) 661-667.

23. Mohamoud M. A. (2014). Unexpected Redox Enhancement and Electrochemical Pseudocapacitance Performance of Polyaniline/poly(vinyl alcohol) (PAn/PVA) Composite Films. Electrochim. Acta, 139 (1) 201-208.

24. Guo H., Zhu H., Lin H., and Zhang J. (2008). Synthesis of polyaniline/multi-walled carbon nanotube nanocomposites in water/oil microemulsion. Mater. Lett., 62 (24) 3919-3921.

25. Hristodor CM., Vrinceanu N., Pode R., Copcia VE., Botezatu E., and Popovici E. (2013). Preparation and thermal stability of $\mathrm{Al} 2 \mathrm{O} 3$-clay and $\mathrm{Fe} 2 \mathrm{O} 3$-clay nanocomposites, with potential application as remediation of radioactive effluents. J. Therm. Anal. Calorim., 111 (conference special issue) $1227-1234$.

26. Garai A., Biplab K., Kuila F., and Nandi A. K. (2006). Montmorillonite Clay Nanocomposites of Sulfonic Acid Doped Thermoreversible Polyaniline Gel: Physical and Mechanical Properties. Macromolecules, 39 (16) 5410-5418.

27. Chrissafis K., Pavlidou E., Paraskevopoulos KM., Beslikas T., Nianias N., and Bikiaris D. (2011). Enhancing mechanical and thermal properties of PLLA ligaments with fumed silica nanoparticles and montmorillonite. J. Therm. Anal. Calorim., 105 (1) 313-323.

28. Giannelis P. (1999). Polymer layered silicate nanocomposites. Adv. Mater., 8 (1) 29-35.

29. Giannelis EP. (1998). Polymer-layered silicate nanocomposites synthesis, properties and applications. Appl. Organomet. Chem., 12 (10-11) 675-680.

30. Mok Lee S., and Tiwari D. (2012). Organo and inorgano-organo-modified clays in the remediation of aqueous solutions: An overview. Appl. Clay Sci., 59-60, 84-102.

31. Peng Liu. (2007). Polymer modified clay minerals: A review. Appl. Clay Sci., 38 (1-2) 64-76.

32. Darshan P. and Suresh P. D. (2012). Polymer in Sustainable Energy. J. Miner. and Mat. Char. and Eng., 11, 661-666.

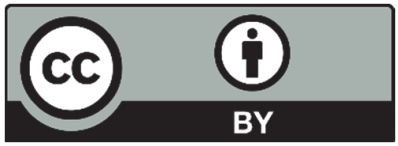

(C) 2017 by the authors; licensee Growing Science, Canada. This is an open access article distributed under the terms and conditions of the Creative Commons Attribution (CC-BY) license (http://creativecommons.org/licenses/by/4.0/). 